\title{
A Computational Risk Assessment Model for Breakwaters
}

\author{
Can Elmar Balas \\ Gazi University, Faculty of Engineering and Architecture, \\ Civil Engineering Department, 06570 Ankara, Turkey \\ cbalas@gazi.edu.tr
}

\begin{abstract}
In the reliability-risk assessment, the second order reliability index method and the Conditional Expectation Monte Carlo (CEMC) simulation were interrelated as a new Level III computational approach in order to analyse the safety level of the vertical wall breakwaters. The failure probabilities of sliding and overturning failure modes of the Minikin method for breaking wave forces were forecasted by approximating the failure surface with a second-degree polynomial having an equal curvature at the design point. In this new computational approach, for each randomly generated load and tide combination, the joint failure probability reflected both the occurrence probability of loading condition and the structural failure risk at the limit state. This new approach can be applied for the risk assessment of vertical wall breakwaters in short CPU durations of portable computers.
\end{abstract}

\section{Introduction}

In the structural design of vertical wall breakwaters, two methods have been widely applied in European countries. The first method is the First Order Mean Value Approach (FMA) [1], and the second one is the Hasofer-Lind second order reliability (HL) index. The partial coefficient system utilizes the former and the latter has been employed to compare risk levels of rubble mound and vertical wall structures [2]. Goda and Tagaki [3] suggested a reliability design criteria in which the Monte Carlo simulation of expected sliding distance was carried out for caisson breakwaters.

The reliability-risk assessment of Ereğli harbor main breakwater involves the second order reliability index $\left(\beta_{\mathrm{II}}\right)$ method interrelated with CEMC simulation as a Level III method. In this technique, uncertainties that affected most of the variables in the design were incorporated throughout the lifetime of structures by the use of the simulation of design conditions, i.e. the water level change due to tidal action and the random wave action. This proposed Level III computational methodology was compared with the individual application of $\beta_{\mathrm{II}}$ (Level II) method.

\section{Computational Risk Model}

The safety of vertical wall breakwater was evaluated by modelling random resistance and load variables with common probability distributions at their limit-state. The primary variable vector $\mathbf{z}$ in the normalized space indicates these random variables. 
The functional form of the basic variables consistent with the limit state is the failure function denoted by: $g(\mathbf{z})=\left(\mathrm{z}_{1}, \mathrm{z}_{2}, \ldots, \mathrm{z}_{\mathrm{n}}\right)$. The safety of the structure can be assured by designating an admissible value of the probability of achieving the limit state defined by: $g(\mathbf{z})=0$. In the reliability-based study, the second-order reliability index method was utilized, in which the failure surface was approximated by a rotational parabolic surface. The parabolic limit state surface in standard normal space, $g(\mathbf{z})$ [4] was taken in the model as follows:

$$
\mathrm{g}(\mathbf{z}) \approx \mathrm{a}_{0}+\sum_{\mathrm{i}=1}^{\mathrm{n}} \mathrm{b}_{\mathrm{i}} \mathrm{z}_{\mathrm{i}}+\sum_{\mathrm{i}=1}^{\mathrm{n}} \mathrm{c}_{\mathrm{i}} \mathrm{z}_{\mathrm{i}}^{2}
$$

where $\mathrm{a}_{0}, \mathrm{~b}_{\mathrm{i}}$, and $\mathrm{c}_{\mathrm{i}}$ are the regression coefficients of the second-order polynomials; $\mathrm{z}_{\mathrm{i}}$ are the standardized normal random variables and $\mathrm{n}$ is the number of random variables. Regression coefficients were obtained by using the response surface approach in standard normal space [5]. The positive sum of the principle curvatures of limit state surface at the design point $\left(\mathbf{z}^{*}\right)$ was expressed as:

$$
\begin{gathered}
\mathrm{K}_{\mathrm{s}}=\frac{2}{|\nabla \mathrm{g}|} \sum_{\mathrm{i}=1}^{\mathrm{n}} \mathrm{c}_{\mathrm{i}}\left[1-\frac{1}{|\nabla \mathrm{g}|^{2}}\left(\mathrm{~b}_{\mathrm{i}}+2 \mathrm{c}_{\mathrm{i}} \mathrm{z}_{\mathrm{i}}^{*}\right)^{2}\right] \\
|\nabla \mathrm{g}|=\sqrt{\sum_{\mathrm{i}=1}^{\mathrm{n}\left(\mathrm{b}_{\mathrm{i}}+2 \mathrm{c}_{\mathrm{i}} \mathrm{z}_{\mathrm{i}}^{*}\right)^{2}}} \\
\beta_{\mathrm{II}}=-\phi^{-1}\left[\phi\left(-\beta_{\mathrm{I}}\right)\left(1+\frac{\varphi\left(\beta_{\mathrm{I}}\right)}{\mathrm{R} \phi\left(-\beta_{\mathrm{I}}\right)}\right)^{-\frac{\mathrm{n}-1}{2}\left(1+\frac{2 \mathrm{~K}_{\mathrm{s}}}{10\left(1+2 \beta_{\mathrm{I}}\right)}\right)}\right]
\end{gathered}
$$

where, $\beta_{\mathrm{II}}$ is the second-order reliability index, $\mathrm{R}$ is the average principal curvature radius expressed as $\mathrm{R}=(\mathrm{n}-1) / \mathrm{K}_{\mathrm{s}}, \beta_{\mathrm{I}}$ is the first order reliability index $\beta_{\mathrm{I}}=\boldsymbol{\alpha}^{\mathrm{T}} \mathbf{z}^{*} ; \Phi$ is the standard normal distribution function, $\varphi$ is the standard normal probability density function, $\boldsymbol{\alpha}$ is the directional vector at the design point. The structural performance of the breakwater under the affect of wave loading was investigated by utilizing the Conditional Expectation Monte Carlo (CEMC) simulation. The exceedance probability $\left(\mathrm{P}_{\mathrm{f}}\right)$ of failure damage level was obtained by utilizing the control random variable vector of $\mathbf{z}_{\mathrm{i}}=\left(\mathrm{z}_{\mathrm{i} 1}, \mathrm{z}_{\mathrm{i} 2}, \ldots, \mathrm{z}_{\mathrm{ik}}\right)$ as follows:

$$
P_{f}=E_{z_{j}: j=1,2, \ldots, n \text { and } j \neq i}\left[P_{f}\left(z_{i}\right)\right]
$$

where, $E[$.$] is the conditional expectation (mean) and \mathrm{P}_{\mathrm{f}}\left(\mathbf{z}_{\mathrm{i}}\right)$ is the failure probability evaluated for $\mathrm{z}_{\mathrm{i} 1}, \mathrm{z}_{\mathrm{i} 2}, \ldots, \mathrm{z}_{\mathrm{ik}}$, by satisfying the conditional term in eqn (6) for the last control variable as follows: 


$$
P_{f}\left(z_{i k}\right)=\operatorname{Pr}\left[z_{i k}<g_{i k}\left(z_{j}: j=1,2, \ldots, n \& j \neq i\right)\right]
$$

where, $\mathrm{k}$ is the number of control variables in the simulation. A computer program was developed for the simulations that repetitively reproduced breakwater performance at the limit state condition until the specified standard mean error of convergence $(\varepsilon)$ was satisfied. The limit state equations for breaking wave forces acting on the vertical wall breakwaters were derived in this study from the Minikin's method [6] as illustrated in Figure (1). For sliding failure mode, the limit state equation utilized in the model was [7]:

$$
\begin{gathered}
g=\mu_{f}\left[B h_{S} \gamma_{C}-B d_{S} \gamma_{o}-\frac{1}{4} \gamma_{o} B H_{b}\right]-\frac{101}{3} \gamma_{o} \frac{d_{s}\left(d_{s}+d\right)}{d_{d}} H_{b}^{2}-\frac{1}{2} \gamma_{o} d_{s} H_{b} \\
-\frac{1}{8} \gamma_{o} H_{b}^{2}=0
\end{gathered}
$$

The limit state equation for the overturning failure mode was obtained as:

$$
\begin{aligned}
\mathrm{g}= & \left(\frac{\mathrm{h}_{\mathrm{S}} \mathrm{B}^{2}}{2}\right) \gamma_{\mathrm{c}}-\left[\left(\frac{1}{4} \mathrm{~d}_{\mathrm{S}}^{2} \gamma_{0}+\frac{1}{6} \gamma_{0} \mathrm{~B}^{2}\right) \mathrm{H}_{\mathrm{b}}+\left(\frac{101}{3} \frac{\gamma_{0}}{\mathrm{~L}_{\mathrm{d}} \mathrm{d}} \mathrm{d}_{\mathrm{S}}^{3}+\frac{101}{3} \frac{\gamma_{0}}{\mathrm{~L}_{\mathrm{d}}} \mathrm{d}_{\mathrm{S}}^{2}\right.\right. \\
& \left.\left.+\frac{1}{8} \gamma_{\mathrm{o}} \mathrm{d}_{\mathrm{s}}\right) \mathrm{H}_{\mathrm{b}}^{2}+\left(\frac{1}{48} \gamma_{\mathrm{o}}\right) \mathrm{H}_{\mathrm{b}}^{3}+\left(\frac{1}{2} \mathrm{~d}_{\mathrm{s}} \mathrm{B}^{2} \gamma_{\mathrm{o}}\right)\right]=0
\end{aligned}
$$

In eqns (7) and (8), $d_{S}$ is the depth from still water level, $h_{s}$ is the height of vertical wall breakwater, $B$ is the width of wall, $\mu_{\mathrm{f}}$ is the coefficient of friction, $\gamma_{\mathrm{o}}$ is the weight per unit volume of seawater, $\gamma_{c}$ is the weight per unit volume of concrete, $\mathrm{H}_{\mathrm{b}}$ is the breaking wave height, $\mathrm{h}_{\mathrm{C}}$ is the breaker crest taken as $\mathrm{H}_{\mathrm{b}} / 2, \mathrm{P}_{\mathrm{m}}$ is the maximum pressure acting at the SWL, $d$ is the depth at a distance one wavelength seaward of the structure, $\mathrm{L}_{\mathrm{d}}$ is the wavelength at the water of depth $\mathrm{d}$.

In the application of the suggested Level III method, the offshore wave height was randomly generated and a linear wave transformation was carried out to obtain the design load of the structure. Then, the reliability of the structure was investigated (on average 30,000 times) by the $\beta_{\mathrm{II}}$ method at the limit state. As a result, the joint failure risk reflected the occurrence probabilities of wave loading and the limit state for each random load combination generated in the simulation. Then, the $\beta_{\text {II }}$ method was applied individually to the case study as a Level II approach and the results obtained from these methods were compared with each other.

\section{Model Application}

A commercial harbor will be constructed in Marmara Ereğlisi on the inland Sea of Marmara of Turkey (Figures 2 and 3). The basic parameters in the design are listed in Table (1) with the mean $(\mu)$ and standard deviation $(\sigma)$ of normally distributed random variables. 

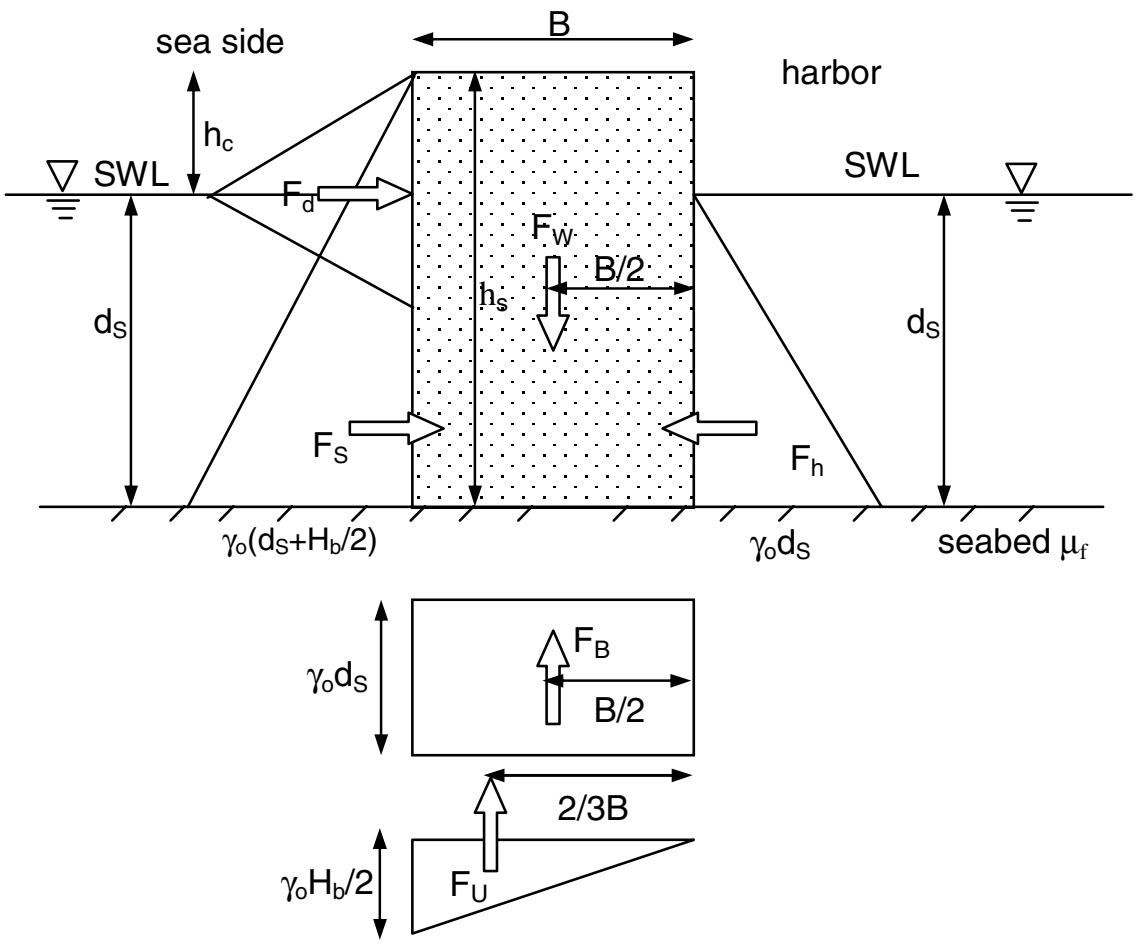

Fig. 1. Breaking wave forces

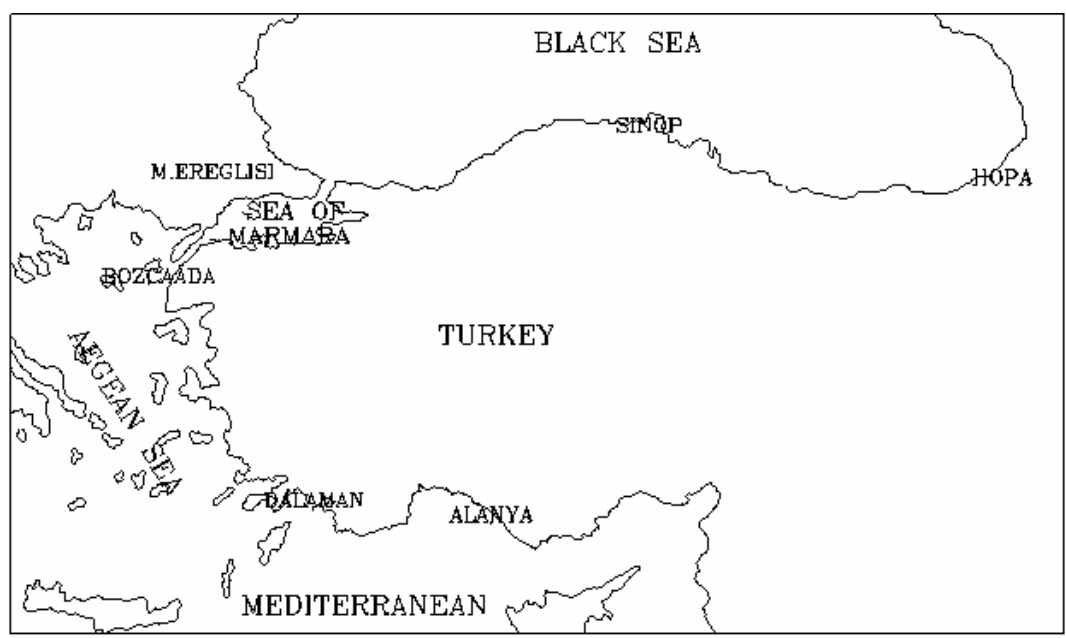

Fig. 2. Locations of recently planned harbours in Turkey 
Table 1. Design parameters for the breakwater

\begin{tabular}{|c|c|}
\hline Design Parameters & Value \\
\hline Height of the structure & $\mathrm{h}_{\mathrm{s}}=17 \mathrm{~m}$ \\
\hline Depth at the toe of the wall & $\mathrm{d}_{\mathrm{s}}=6.5 \mathrm{~m}$ \\
\hline Depth at distance one wave length seaward & $\mathrm{d}=8 \mathrm{~m}$ \\
\hline Wave length at water depth $d$ & $\mathrm{~L}_{\mathrm{d}}=76 \mathrm{~m}$ \\
\hline Weight per unit volume of sea water & $\gamma_{0}=1.02 \mathrm{t} / \mathrm{m}^{3}$ \\
\hline Weight per unit volume of concrete $\left(t / \mathrm{m}^{3}\right)$ & $\mu=2.4 \mathrm{t} / \mathrm{m}^{3} \quad \sigma=0.1 \mathrm{t} / \mathrm{m}^{3}$ \\
\hline $\begin{array}{l}\text { Coefficient of friction } \\
\text { (normally distributed) }\end{array}$ & $\mu=0.64$ \\
\hline Wave height (Weibull-Rayleigh) H (m) & $\beta=1.55$ \\
\hline
\end{tabular}

Table 2. Annual maximum significant wave characteristics of the site

\begin{tabular}{cccccccc}
\hline $\mathrm{M}$ & $\mathrm{Hs}$ & $\mathrm{Ts}$ & $\mathrm{L}_{\mathrm{o}}$ & $\mathrm{Kr}$ & $\mathrm{H}_{\mathrm{o}}{ }^{\prime}$ & $\mathrm{H}_{\mathrm{b}} / \mathrm{H}_{\mathrm{o}}{ }^{\prime}$ & $\mathrm{H}_{\mathrm{b}}$ \\
\hline 1 & 3,170 & 8,072 & 101,641 & 1,000 & 3,170 & 1,11 & 3,519 \\
2 & 3,200 & 8,096 & 102,256 & 0,974 & 3,116 & 1,11 & 3,459 \\
3 & 3,430 & 8,278 & 106,901 & 1,000 & 3,430 & 1,1 & 3,773 \\
4 & 3,780 & 8,539 & 113,76 & 1,000 & 3,780 & 1,09 & 4,120 \\
5 & 3,820 & 8,568 & 114,528 & 1,000 & 3,820 & 1,09 & 4,164 \\
6 & 3,900 & 8,625 & 116,058 & 0,973 & 3,793 & 1,09 & 4,134 \\
7 & 4,540 & 9,055 & 127,911 & 0,972 & 4,411 & 1,08 & 4,764 \\
8 & 4,880 & 9,267 & 133,962 & 0,984 & 4,802 & 1,08 & 5,186 \\
9 & 4,900 & 9,279 & 134,313 & 0,984 & 4,822 & 1,08 & 5,207 \\
10 & 5,070 & 9,381 & 137,277 & 0,984 & 4,989 & 1,08 & 5,388 \\
11 & 5,520 & 9,640 & 144,955 & 0,984 & 5,432 & 1,07 & 5,812 \\
12 & 6,020 & 9,911 & 153,227 & 0,984 & 5,924 & 1,06 & 6,279 \\
13 & 6,650 & 10,231 & 163,305 & 0,984 & 6,544 & 1,05 & 6,871 \\
\hline
\end{tabular}

The wave height was modeled by a joint Weibull-Rayleigh probability distribution with the scale $(\alpha)$ and shape $(\beta)$ parameters listed in Table (1) by using the wave characteristics listed in Table (2) [8]. In Table (2), $\mathrm{H}_{\mathrm{b}}$ is the breaker height at construction depth, $\mathrm{H}_{\mathrm{o}}{ }^{\prime}$ is the unrefracted deep-water wave height, $\mathrm{M}$ is the plotting position, $\mathrm{Kr}$ is the linear refraction coefficient, $\mathrm{Hs}$ and $\mathrm{Ts}$ are the annual maximum significant deep-water wave height and period, respectively. The new Level III reliability approach, in which the second order reliability index $\left(\beta_{\text {II }}\right)$ and the Conditional Expectation Monte Carlo (CEMC) simulation were interrelated, was suggested to handle the uncertainties inherent in wave data and design methodology 
[9]. Wave characteristics of the site were randomly generated by simulation. Afterwards, the failure mode probability was predicted by the parabolic limit state surface having the identical curvature at the design point with the higher degree failure surface. The mean $(\mu)$ and the standard deviation $(\sigma)$ of the wave height distribution were $\mu_{\mathrm{H}}=4.77 \mathrm{~m}$ and $\sigma_{\mathrm{H}}=0.95 \mathrm{~m}$, respectively. Probabilities of failure of the Ereğli vertical wall breakwater in 50 years of lifetime obtained by the suggested Level III approach for both sliding and overturning failure criteria are given in Figure (4) in which sliding criterion governs the design. The sensitivity study carried out by using a rank correlation method reveals that the overturning failure function is sensitive to the wave height with a correlation coefficient of $\mathrm{Rc}=-0.84$ (load variable) obtained by Level II and Level III methods for sliding criterion under breaking wave forces and to the weight per unit volume of concrete with $\mathrm{Rc}=0.46$ (resistance variable). The sliding failure function is sensitive to the wave height with $\mathrm{Rc}=-0.73$ (loading variable), to the weight per unit volume of concrete $R c=0.22$ (resistance variable), and to the coefficient of friction with $\mathrm{Rc}=0.57$.

For sliding failure criterion, the probability of failure determined from Level II reliability method is lesser than the probability of failure obtained from Level III reliability method with a root mean square error of 0.25 and a bias of -0.17 (Figure 5). For overturning failure criterion, the probability of failure obtained from Level III reliability method is greater than the probability of failure obtained from Level II method with a root mean square error of 0.32 and a bias of -0.17 .

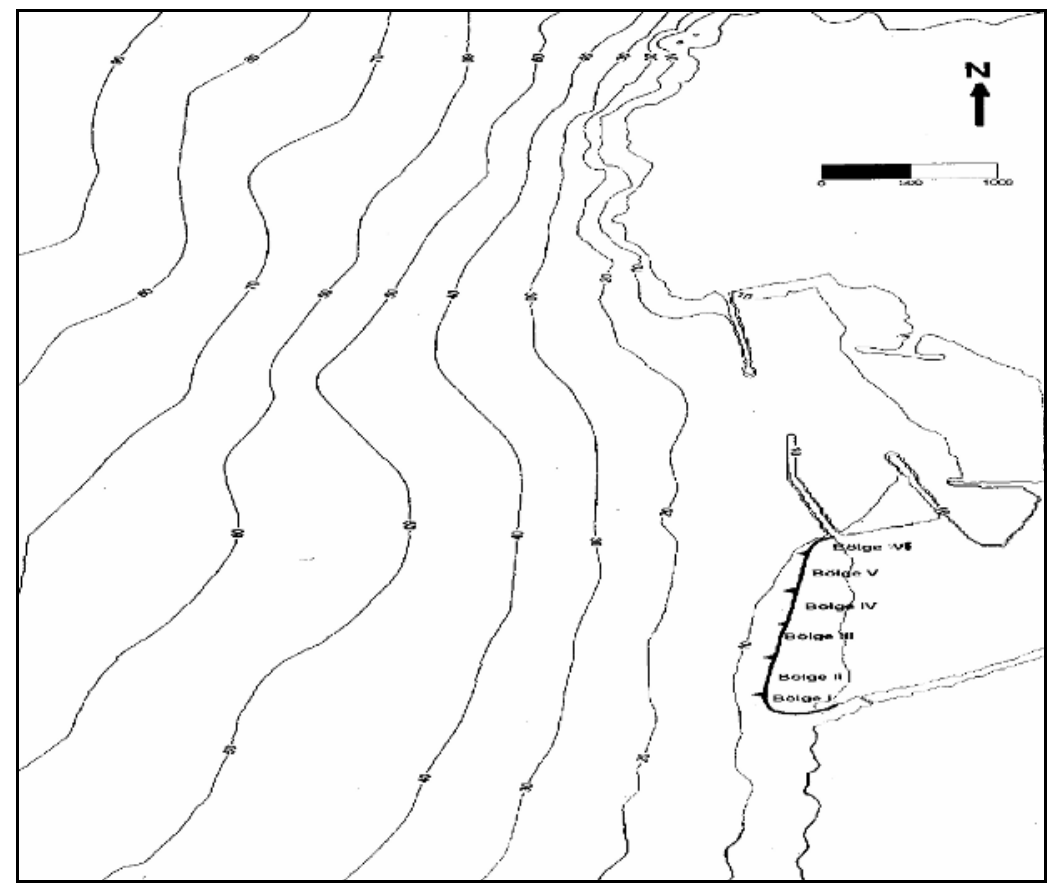

Fig. 3. Ereğli (Marmara) harbour 


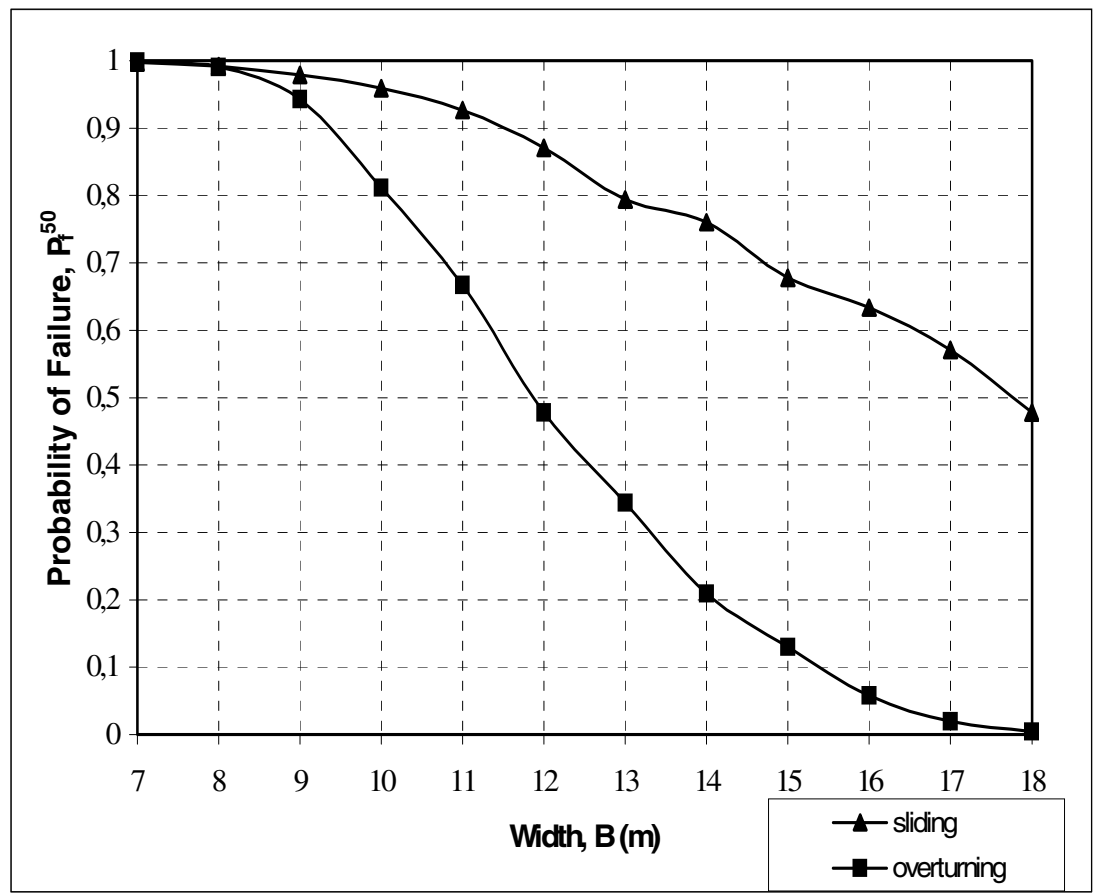

Fig. 4. Failure risk of the Ereğli vertical wall breakwater in lifetime

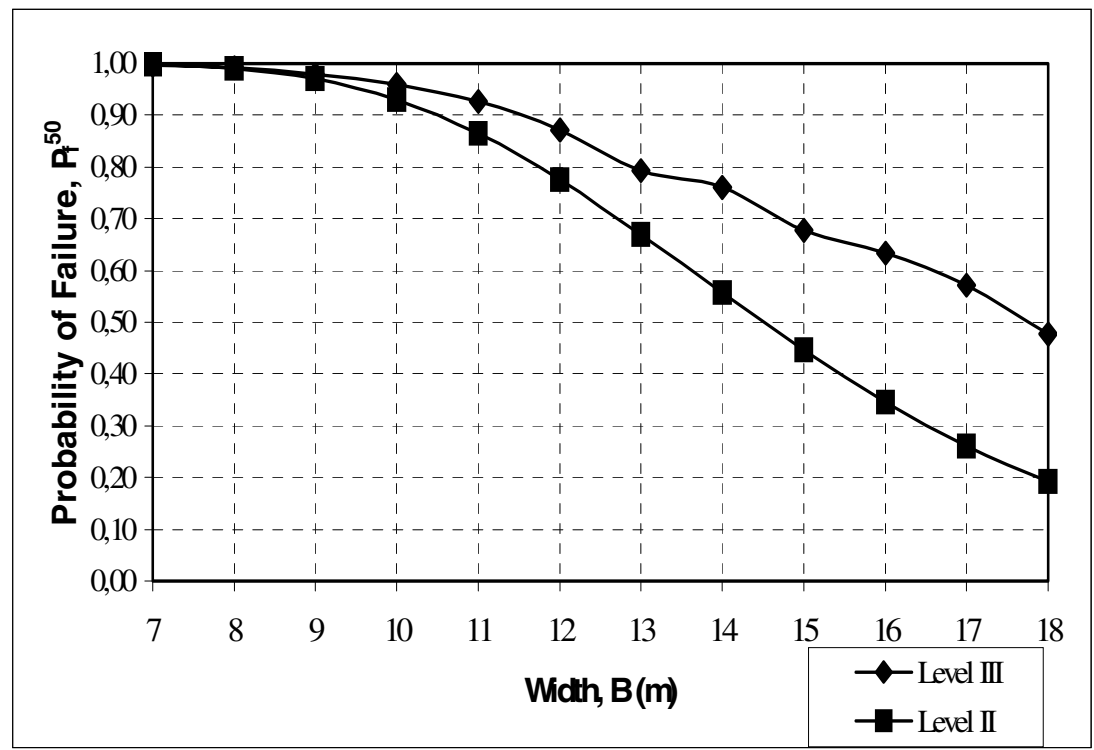

Fig. 5. Comparison of failure probability of vertical wall breakwater in a lifetime of 50 years obtained by Level II and Level III methods for sliding criterion under breaking wave forces 


\section{Conclusions}

A new computational simulation methodology was presented for the design of breakwaters. For the case study at Ereğli, results obtained from Level II method deviated from results obtained by simulation. Therefore, structural reliability evaluated by using Level II method was considered as approximate, when compared to the Level III method presented in this paper. The type of distribution (Normal or extreme value) in design parameters of the failure function also effected the reliability evaluations irrespective of the design level. As a result, the reliability of vertical wall structures was highly variable and depended upon the unpredictable nature of coastal storms, the reliability method and distributions utilized in the design.

This new computational method has advantages in practical design applications, since the random behaviour of structural performance in lifetime can be estimated at the planning stage. The new computational approach applied in this paper within few minutes of CPU time in a portable computers, was recommended for the risk assessment of vertical wall breakwaters.

\section{References}

1. Burcharth, H.F. and Sorensen J.D., Design of vertical wall caisson breakwater using partial safety factors. Proc. of the $26^{\text {th }}$ International Conference on Coastal Engineering, ASCE, Copenhagen, Denmark (1998) 2138-2151.

2. Burcharth, H.F. and Sorensen J.D., The PIANC safety factor system for breakwaters. Proc. of the Coastal Structures'99, ed. I.J. Losada, Balkemare, Spain, (1999) 1125-1144.

3. Goda Y. and Tagaki H., A Reliability design method of caisson breakwaters with optimal wave heights. Coastal Engineering Journal, 42 (4), 357-387 (2000).

4. Balas C.E. \& Ergin A., A sensitivity study for the second order reliability based design model of rubble mound breakwaters, Coastal Engineering Journal, 42, (1) 57-86 (2000).

5. Hong, H.P., Simple approximations for improving second-order reliability estimates, Journal of Engineering Mechanics, 125 (5), 592-595 (1999).

6. CERC, Shore Protection Manual, Coastal Engineering Research Center, U.S. Army, Corps of Engineers, USA (1984).

7. İçmeli, F., Risk assessment of vertical wall breakwaters using sliding and overturning design criteria for breaking waves, MSc. Thesis, Middle East technical University, Ankara, Turkey (2002).

8. Özhan, E., Ergin, A., Ergun, U., Yalçıner, A.C., Abdalla, S., \& Yanmaz, M., Hydraulic Research on the Harbor of Marmara Ereğlisi, Middle East Technical University Technical Report, Ankara, Turkey, 57 (1998).

9. Balas, C.E. \& Ergin, A.E. Reliability-Based Risk Assessment in Coastal Projects: A Case Study in Turkey, Journal of Waterway, Port, Coastal and Ocean Engineering, ASCE, (2002). 